\title{
Study of patient complaints reported over 30 months at a large heart centre in Tehran
}

\author{
Jila Manouchehri Moghadam, ${ }^{1}$ Hossein Ibrahimipour, ${ }^{2}$ Ali Sari Akbari, ${ }^{3}$ \\ Mohammad Farahbakhsh, ${ }^{4}$ Zohreh Khoshgoftar ${ }^{1}$
}

${ }^{1}$ Quality Management

Department, Tehran Heart Centre, Tehran University of Medical Sciences, Tehran, Iran ${ }^{2}$ Department of Health Services Management, Mashhad University of Medical Sciences, Mashhad, Iran

${ }^{3}$ Department of Health Management and Economics, Tehran University of Medical Sciences, Tehran, Iran ${ }^{4}$ Medical Institute, Shahid Beheshti University of Medical Sciences, Tehran, Iran

\section{Correspondence to} Dr Hossein Ibrahimipour, Health and Management Department, Faculty of Health, Mashhad University of Medical Sciences, Mashhad 9185763788, Iran; hebrahimip@gmail.com

Accepted 19 December 2009 Published Online First 14 June 2010

\section{ABSTRACT}

Objectives To determine the rate and nature of complaints and the outcomes of the complaint management at a large heart centre in Tehran.

Design A retrospective review of all verbal and written complaints recorded over 30 months.

Setting A large heart centre in Tehran, Iran.

Population All 312105 admissions (47041 inpatients, 138842 outpatients and 126222 ambulatory services) between July 2005 and January 2007 at Tehran Heart Centre, during which the hospital received 1642 verbal and written complaints.

Main outcome measures Proportion of admissions with verbal and written complaints, type of complaints and outcomes of the complaint management.

Results A total of 1642 (5.2 per 1000) complaints were received, of which 1457 (4.64 per 1000) were verbal, and 185 (0.56 per 1000) were in written format. $34.7 \%$ of the complaints were related to admission procedures, followed by $34.1 \%$ communication, $13.8 \%$ waiting time, $6.8 \%$ delay and $4.1 \%$ ignoring the standards of clinical care. Over $90 \%$ of complaints were resolved by explanation or verbal apology, $2.1 \%$ of them led to a change in the process or procedure, and $4.8 \%$ were deemed disapproved claims.

Conclusions The majority of patient complaints in Tehran Heart Centre are related to admission procedures or communication; most of them are verbal and resolved in the early stage as an explanation or apology. The hospital complaint management system has the potential to resolve the majority of such complaints in an early stage.

\section{INTRODUCTION}

Patient satisfaction is an important aspect of the quality of care. Patients normally make complaints when they are not happy with the care they receive. Study of the rate, nature and likely causes of patient complaints is an important step in increasing both patient satisfaction and the quality of healthcare. This subject is considered a priority and has been well studied in many modern health systems, including the USA, the UK and Australia. ${ }^{1-4}$ However, this issue has not yet been well documented in developing countries, particularly in Iran. The aim of this study is to analyse all the complaints recorded over a 30 -month period at a large heart centre in Tehran (Tehran Heart Centre (THC)) to determine the rate of complaints, their categories and the outcomes of the complaint management. In this paper, complaint has been defined as any resort to the hospital Complaint
Department to denounce the patient or their family's dissatisfaction and discontent about the hospital staff, units or services.

\section{METHODS \\ Setting}

This study was conducted at THC between March and August 2008. THC is a 442-bed governmental teaching hospital with 850 medical and 400 nonmedical staff. It is one of the major public cardiac disease centres in the country that provides a wide range of diagnostic, medical and surgical services in all the main cardiac disciplines. This hospital was inaugurated in early 2002 and was awarded the ISO9001:2000 certificate in October 2004 from the British Standard Institution (BSI), and since then has continued to perform its activities in compliance with the ISO9001:2000 principles.

\section{Process of handling complaints in the hospital}

Since May 2004, the hospital has set up a Complaint Department as a part of quality improvement system that is responsible for any complaints received from the patients, staff and visitors. The Complaint Department benefits from a full-time Complaint Responder who is selected from the experienced employees according to the following criteria:

- being familiar with the work flow of different hospital units;

- good public relations and desirable work relations with the majority of the staff;

- being tolerant and a good listener.

If a patient or their family refers to the Complaint Department to complain about any undesirable conditions, the Complaint Responder will record a brief summary of the case in an initial form and will try to settle the conflict by any of the following methods, depending on the type of complaint (figure 1):

- in cases such as the referee's unawareness of the hospital routine work flow leading to dissatisfaction or discontent: giving some explanations about work flow and the legal or intraorganisational provisions;

- in such cases where limitations of hospital facilities would lead to dissatisfaction or protest (such as the definite capacity of the clinics, surgery and so on): giving explanations about these limitations;

- in cases where staff behaviour leads to dissatisfaction or discontent: abating the dissatisfaction of the patient by listening to their claims and convincing them that the hospital would plan and act to reduce such behaviours as much as possible. 


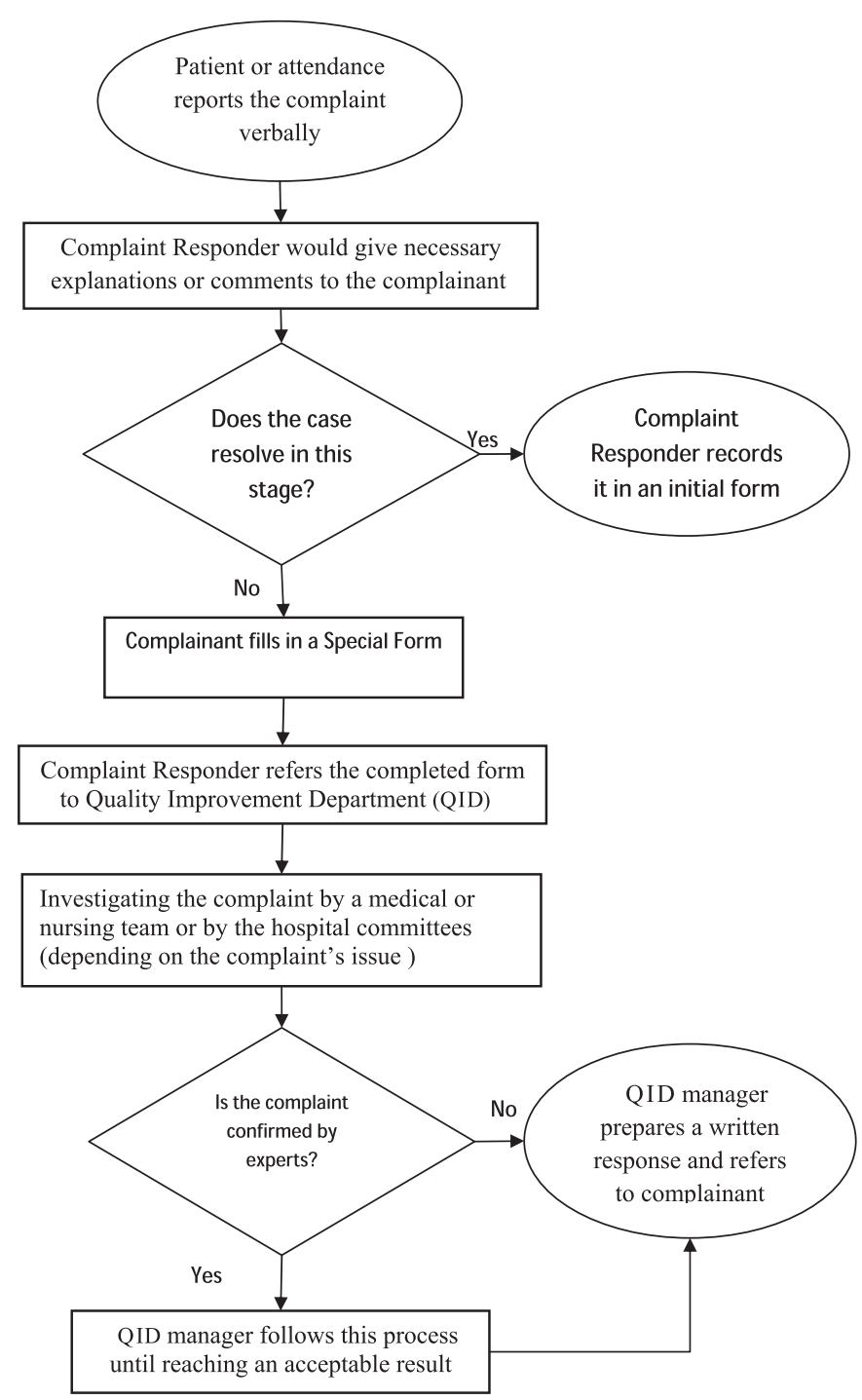

Figure 1 Process of handling complaints at Tehran Heart Centre.

If the complaint is not resolved at this stage, the Complaint Responder would give them a new structured form called Special Form (SF) so that they could write down their complaint. The completed forms are then sent to the Quality Improvement Department (OID) to be further investigated by its manager, who is a highly qualified Health Care Management graduate. At this stage, depending on the type and nature of the complaint, the OID manager will decide if the complaint should be further investigated by a medical or nursing team or should be reviewed by the relevant hospital committee and will act accordingly. With regard to the result of the investigations, a combination of the following actions might be implemented: verbal apology, correction in policy, process or procedure and/or compensation. In cases where the complaint does not have enough ground, it would be regarded as a 'disapproved claim'. In all cases, the result of the complaint review would be recorded on the Special Form, and the relevant response would be given to the complainant by the OID manager (figure 1). It is important to note that during this process, staff are instructed to behave in a respectful manner towards the patients/referees, so that they feel the hospital authorities respect their rights, opinions and feelings and try to learn lessons from reported cases to improve the quality of the services.

\section{Sampling and design}

In this study, all patient complaints reported verbally or in written form to the Complaint Department between July 2005 and January 2007 (30 months) were retrospectively reviewed. In order to estimate the rate of complaints, the central database of the hospital was used to identify the total number of admissions (including inpatients, outpatients and ambulatory services) during the same time.

\section{Data collection process and analysis}

THC has designed and used the initial and special forms for recording patient complaints and the outcomes of the complaint management. We initially reviewed 50 recorded complaints for which both the initial and special forms had been completed and, according to the type of data available on these records, designed a classification for analysing and reporting the result of this study. We classified the complaints into 10 complaint groups and six output groups, as presented in table 1. These classifications are relatively similar to the classifications used by some previous studies. ${ }^{1-4}$

\section{RESULTS}

\section{Rate of complaints}

Over the 30-month study period, a total number of services (312 105) were delivered to patients, including 47041 inpatients, 138842 outpatients and 126222 ambulatory services. During this time, the hospital received a total of 1642 (5.2 per 1000) complaints, including 1457 (4.6 per 1000) verbal and 185 (0.56 per 1000) written complaints.

\section{Types of complaints}

Of a total of 312105 patient admissions to the hospital during the study period, 1642 complaints were reported by patients or their representatives, of which 1457 (89.2\%) were verbal, and 185 (10.8) were in written form (table 2), making the rate of written complaints 0.56 per 1000 and the rate of verbal complaints 4.6 per 1000 admissions.

Sixty-four $(34.5 \%)$ of written complaints were related to communication failures, followed by $47(25.4 \%)$ related to ignoring the standards of clinical care, $17(9.2 \%)$ related to inadequate attention to patient and $16(8.6 \%)$ related to a delay in delivery of general services. Five hundred and fifty-eight (38.3\%) of the 1457 verbal complaints were related to admission/ appointment procedures, followed by 497 (34.1\%) to communication and $226(15.5 \%)$ to waiting time. Putting all the verbal and written complaints together, issues related to admission/ appointment procedures were the most common type of complaints $(34.7 \%)$, followed by failure in communication (34.1\%) and waiting time (13.8\%), (table 2$)$.

Of the 561 verbal and written complaints related to the communication failure, $218(38.8 \%)$ were complaints about nurses, followed by 110 (19.6\%) about physicians, $83(14.7 \%)$ about nurse assistants, 64 (11.4\%) about secretaries and the remaining $86(15.3 \%)$ about other non-medical staff.

\section{Outcomes of the complaint management}

One thousand four hundred and fifty-eight (88.8\%) complaints including all verbal complaints were resolved by explanation, $35(2.1 \%)$ by verbal apology and $21(1.3 \%)$ by compensation. Sixteen (1\%) of the complaints were unavoidable, and $78(4.8 \%)$ were disapproved claims (table 3). Of the 68 complaints that were related to ignoring the standards of clinical care, $30(44.1 \%)$ were disapproved by experts, 21 (30.9\%) were resolved by explanation, six (8.8\%) resulted in a correction in 
Table 1 Categories of complaints and their examples/definition

\begin{tabular}{|c|c|}
\hline Type of complaints & Examples or definitions \\
\hline Waiting time & $\begin{array}{l}\text { Long waiting list for surgery or other special procedures, waiting in outpatient departments, waiting for the first visit } \\
\text { appointment }\end{array}$ \\
\hline Admission/appointment issues & Lack of coordination in the admission process, restriction in inpatient or outpatient hospital capacity \\
\hline Lack of access to clinical services & Any deficit in access to non-cardiac specialist and special health services for inpatients \\
\hline Inadequate attention to patient & Inadequate attention to patients' scheduled care mostly by clinical staff \\
\hline Ignoring the standards of clinical care & Missed or delayed diagnosis, inappropriate/ inadequate treatment, examination and investigation \\
\hline General facilities deficit & Hospitality, sanitation, air conditioning, clothing, etc \\
\hline Delay in delivery of general services & Delay in delivering services such as preparing medical reports, taking place medical procedures, special consults, etc \\
\hline Communication failures & $\begin{array}{l}\text { Rudeness or insensitive/inappropriate remarks, poor or inadequate communication including inadequate update on medical } \\
\text { condition, inadequate attention to patients' wants, inadequate responsiveness }\end{array}$ \\
\hline Breach of patient's rights & Breach of patient's rights such as respect, privacy, confidentiality, belongings, etc \\
\hline Financial discount requesting & Requesting discount about patients' bill \\
\hline Outcomes of complaints & Examples or definitions \\
\hline Explanation offered and accepted & $\begin{array}{l}\text { Cases in which the complainant has been convinced by the explanations of the complaint responder or the manager of the } \\
\text { Quality Management Department about the conditions or limitations causing dissatisfaction and discontent }\end{array}$ \\
\hline Verbal apology provided & $\begin{array}{l}\text { Verbal apology to the complainant by the physician, nurse or other member of staff who has brought about the patient's } \\
\text { discontent intentionally or unintentionally by inappropriate behaviour or in any other ways }\end{array}$ \\
\hline Resolved by compensation & Compensating for the financial losses of the patient if the expert team accepts \\
\hline Disapproved claim & $\begin{array}{l}\text { Written complaints which are regarded as a disapproved or unreasonable claim after monitoring the manager of the Quality } \\
\text { Management Department and investigations of the expert team }\end{array}$ \\
\hline Unavoidable & $\begin{array}{l}\text { Complaints for which, despite the fact that they are reasonable, no special decision has been made because of the facilities } \\
\text { and conditions of the hospital and the nature of the complaint- for example, cancellation of a surgery due to the absence of } \\
\text { the surgeon or delay in the hospitalisation of the patient due to unpredictable reasons such as a lack of adequate beds at that } \\
\text { time }\end{array}$ \\
\hline Correction in policy, process or procedure & $\begin{array}{l}\text { Adopting some reforms in policies and processes in the hospital or in the way of performing activities in order to reduce the } \\
\text { likelihood of complaints by patients }\end{array}$ \\
\hline
\end{tabular}

policy, process or procedure, four (5.9\%) led to compensation, and four $(5.9 \%)$ were resolved by a verbal apology. None of the complaints led to litigation.

Four hundred and ninety-seven (88.6\%) of the 561 complaints that were related to communication failures were resolved by explanation, 26 (4.6\%) were disapproved claims, and $16(2.9 \%)$ were resolved by verbal apology (table 3$)$. Thirty-four (2.1\%) of all complaints resulted in a change in policy, process or procedure. Communication failures, ignoring the standards of clinical care and inadequate attention to the patients, have changed remarkably, compared with the other types of complaints.

\section{DISCUSSION}

Patients make complaints when they are not happy with the care they receive. In this study, we investigated the proportion of admissions with verbal and written complaints, the type of complaints and the outcomes of the complaint process in THC in a 30 -month period. This is a priority that had not been well considered in Iran.
This study found that about $0.5 \%$ of patients (inpatients or outpatients) admitted at THC reported their dissatisfaction verbally or made a formal written complaint regarding the care they received, and the rate of formal written complaints was 0.56 per 1000 . This is lower than the rate of dissatisfaction $(1.7-2.1 \%)^{5}{ }^{6}$ and comparable with rates of formal complaints $(0.26-2.7 \text { per } 1000)^{1-4} 7-10$ reported in other studies.

Sari et al reviewed 1006 patients admitted in a general NHS hospital and found that for $1.7 \%$ of these patients, dissatisfaction from the care was reported to the hospital reporting system, ${ }^{5}$ and for a further $0.4 \%$ of patients, dissatisfaction was recorded in the patient case notes. ${ }^{6}$ This shows that using different methods may result in different rate of dissatisfaction. In THC, we did not review patient case notes and there was no general incident reporting system. We only reviewed the verbal and written complaints including dissatisfactions reported to the complaint management office. In THC, normally all the cases including dissatisfaction, unmet expectations and complaints were first reported verbally to the complaint

Table 2 Number and percentage of complaints in each category

\begin{tabular}{|c|c|c|c|c|c|c|}
\hline \multirow[b]{2}{*}{ Type of complaints } & \multicolumn{2}{|c|}{ Written } & \multicolumn{2}{|c|}{ Verbal } & \multicolumn{2}{|l|}{ Total } \\
\hline & $\mathbf{N}$ & Percentage & $\mathbf{N}$ & Percentage & $\mathbf{N}$ & Percentage \\
\hline Waiting time & 0 & 0 & 226 & 15.5 & 226 & 13.8 \\
\hline Lack of access to clinical services & 5 & 2.7 & 34 & 2.3 & 39 & 2.4 \\
\hline Inadequate attention to patient & 17 & 9.2 & 0 & 0 & 17 & 1 \\
\hline Ignorance the standards of clinical care & 47 & 25.4 & 21 & 1.4 & 68 & 4.1 \\
\hline Communication failures & 64 & 34.5 & 497 & 34.1 & 561 & 34.1 \\
\hline Breach of patient's rights & 11 & 5.9 & 0 & 0 & 11 & 0.7 \\
\hline Financial discount requesting & 10 & 5.4 & 0 & 0 & 10 & 0.6 \\
\hline Total & 185 & 10.8 & 1457 & 89.2 & 1642 & 100 \\
\hline
\end{tabular}


Table 3 Outcomes of complaint management by categories of complaints

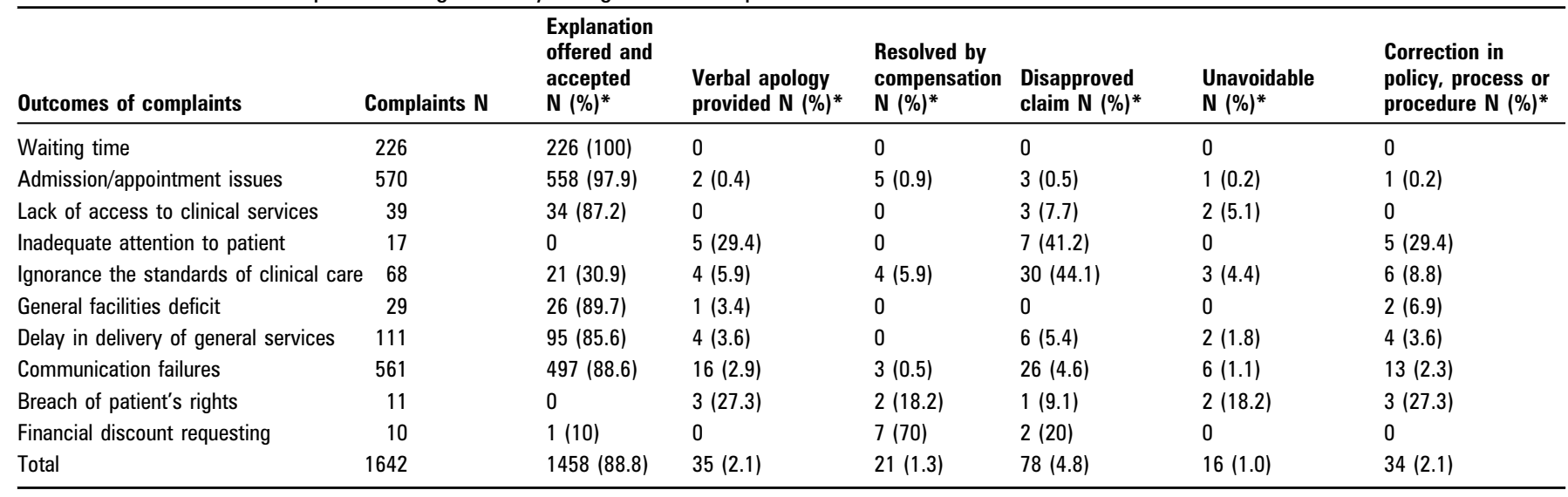

*Numbers in parentheses are percentages of total complaints in each row.

management system. If the case was resolved with some explanations and/or advice, it was recorded in an Initial Form, and no further follow-up was undertaken, but if the case was not resolved, it was transformed to a second Special Form for further investigations. This might be the reason we have found a smaller rate of dissatisfaction and verbal complaints. On the other hand, it is possible that some hospitals have not recorded their verbal complaints resolving by initial explanations in an early stage, and this might be the reason some studies reported a lower rate of complaints. ${ }^{17}$

Why do people report the complaints, and why is this proportion of the complaints resolved with explanation or advice? Friele and Sluijs found that '...the majority of people make complaints mainly to prevent the incident from happening again, restore the complainants' sense of justice or remind the staff what had happened and the effect it had on the patients. ${ }^{11}$ The fact that almost $90 \%$ of all verbal complaints in this study were resolved through explanation is consistent with other study findings. ${ }^{39}$ Friele and Sluijs suggest that for most complainants, having an explanation is more important than an apology; 'They want to know.' 11 In our complaint classification, complaints about communication failures, ignoring the standards of clinical care and inadequate attention to the patients, in this sequence, are the most written complaints, but verbal complaints were mostly related to admission/appointment issues, communication failures and waiting time. Although there is no standard category for classifying patient complaints, and the categories we used were different in some aspects from the previous studies, as a whole the types of complaints found by this study were comparable with those of other studies. $^{1-4} 7-10$ 12-15

We found that more than a quarter of the written complaints were about ignoring the standards of clinical care, which is comparable with the finding of other research (22.5-47\%). ${ }^{1-4} 7914$

Most of these complaints were disapproved claims or were resolved by explanation. The fact that approximately $1 \%$ of all complaints were related to inadequate attention to the patients, and $0.7 \%$ were related to breaches of patients' rights, might suggest that the quality of care is within an acceptable level at THC, and this might be due to the hospital's quality-improvement programmes which have been implemented in the last 5 years in THC, including:

- presence of trained senior specialists 24 h a day 7 days a week;

- using approved clinical protocols and guidelines;

- continuous training programmes for clinical staff;
- regular monitoring and reporting of the main processes quality indicators;

- internal audit;

- using several checklists by clinical and non-clinical supervisors.

Vincent et al have found that the majority of obstetrics complaints resulting in litigation were associated with inexperienced junior staff providing the care without supervision by a senior specialist. ${ }^{16} 17$ A similar study shows that most of the complaints reported to the Medical Council Organization of Tehran were against middle-aged doctors. ${ }^{18}$

We found that more than one-third of all complaints were related to communication failure, which is consistent with the results of other studies (ranging from 26 to 50\%). ${ }^{1-4} 131419$ Studies that have explored the rate and consequences of adverse events have also found communication failure as the main cause of such incidents. ${ }^{20}$ The findings that over $95 \%$ of complaints were resolved by explanation, apology or disapproved claims also suggest that improving staff communication skills may have a great impact on reducing such complaints. ${ }^{19} 1819$

Approximately one-sixth of the complaints were related to waiting time. In many healthcare systems, there are waiting lists, and normally the main reason for the waiting time is a lack of resources. Therefore, a proportion of these complaints may be the result of an unrealistic expectation by the patient, but because patients' overall satisfaction is partly determined by the perceived rather than actual waiting time, this is important to consider and to explain to the patients. ${ }^{4}$ Almost all of these complaints were resolved by an explanation of the restriction in hospital capacity. As mentioned earlier, THC is a very famous public and highly specialised cardiac centre with a high rate of referral for both medical and surgical services. This makes it impossible to admit all the patients on time. Elective cases have to wait 4-8 months before surgical treatment.

Our findings on the complaints that resulted in a change in policy, process or procedure $(2.1 \%)$ are comparable with the results $(1.7 \%)$ of the study carried out by Taylor et al. ${ }^{3}$

The most important actions we have performed in this regard at THC are:

- arranging special training courses focused on improving the communication skills;

- organising appointments and common committees with the units having the same problems;

- providing continuous feedback to the units and departments regarding the complaints; 
- provision and notification of work instructions;

- changes in some working methods.

\section{LIMITATIONS}

Several limitations of this study need to be mentioned. The complex nature of the complaints that makes the classification difficult and the lack of standard classification system as well as a standard scale to analyse complaints validity are among the limitations. Such objective standards can help to decrease measurement bias and make the data from different institutions more comparable. By developing a system, institutions can compare their data in a standardised manner, which would facilitate their comparison and increase the value of information that can help us to make new policies to improve the quality of patient care.

\section{CONCLUSION}

This study shows that complaints are relatively common in THC, as in other hospitals in other countries, and similarly the majority are related to admission or communication failures, although most of them are verbal, resolved at an early stage by an explanation or apology. A review of complaints has the potential to provide useful information for their prevention and improving the quality of clinical services. A study of the complaints may help us identify the gaps in our services and make necessary corrections in the policies or procedures.

Acknowledgements The authors would like to thank A-A Karimi and M Salarifar, Head and Deputy of Education of Tehran Heart Centre, for their support and encouragement. We thank the staff of the Complaints and Quality Management Department of Tehran Heart Centre for their cooperation in data gathering phase.

Competing interests None.

Patient consent Obtained.

Provenance and peer review Not commissioned; externally peer reviewed.

\section{REFERENCES}

1. Anderson K, Allan D, Finucane P. A 30-month study of patient complaints at a major Australian hospital. J Qual Clin Pract 2001;21:109-11.

2. Taylor DMD, Wolfe RS, Cameron PA. Analysis of complaints lodged by patients attending Victorian hospitals, 1997-2001. Med J Aust 2004;181:31-5.

3. Taylor DMD, Wolfe R, Cameron PA. Complaints from emergency department patients largely result from treatment and communication problems. Emerg Med 2002:14:43-9.

4. Wong LL, Ooi SBS, Goh LG. Patients'complaints in a hospital emergency department in Singapore. Singap Med J 2007;48:990-5.

5. Sari ABA, Sheldon TA, Cracknell A, et al. Sensitivity of routine system for reporting patient safety incidents in an NHS hospital: retrospective patient case note review. BMJ 2007;334:79.

6. Sari ABA, Sheldon TA, Cracknell A, et al. Extent, nature and consequences of adverse events: results of a retrospective casenote review in a large NHS hospital. Oual Saf Health Care 2007:16:434-9.

7. Anderson K, Allan D, Finucane P. Complaints concerning the hospital care of elderly patients: a 12-month study of one hospital's experience. Age Ageing 2000;29:409-12.

8. Chavan R, Porter C, Sandramouli S. Formal complaints at an eye hospital: a threeyear analysis. Clin Governance Int J 2007;12:85-92.

9. Kadzombe EA, Coals J. Complaints against doctors in an accident and emergency department: a 10-year analysis. BMJ 1992:9:134-42.

10. Ooi SBS. Emergency department complaints: a ten-year review. Singap Med J 1997:38:102-7.

11. Friele RD, Sluijs EM. Patient expectations of fair complaint handling in hospitals: empirical data. BMC Health Serv Res 2006;6:106.

12. Daniel AE, Burn RJ, Horarik S. Patients'complaints about medical practice. Med $J$ Aust 1999;170:598-602.

13. Taylor D, Kennedy MP, Virtue E, et al. A multifaceted intervention improves patient satisfaction and perceptions of emergency department care. Int $J$ Qual Health Care 2006;18:238-45

14. Siyambalapitiya S, Caunt J, Harrison N, et al. A 22 month study of patient complaints at a National Health Service hospital. Int J Nurs Pract 2007:13:107-10.

15. Natangelo R. Clinicians' and managers' responses to patients' complaints: a survey in hospitals of the Milan area. Clin Governance Int J 2007;12:260-6.

16. Vincent C, Bark $P$, Jones $A$, et al. The impact of litigation on obstetricians and gynaecologists. J Obstet Gynaecol 1994;14:381-7.

17. Naveh E, Stern Z. How quality improvement programs can affect general hospital performance. Qual Assurance 2005;18:249-70.

18. Jafarian A, Parsapour A, Haj-Tarkhani A, et al. A survey of the complaints entering the Medical Council Organization of Tehran in three time periods: the years ending on 20 March 1992, 20 March 1997 and 20 March 2002. J Med Ethics 2009;2:9.

19. Bazrafkan L, Shokrpour N, Tabeie SZ. A Survey of patients' complaints against physicians in a five year. J Med Educ 2009;12:23-8.

20. Vincent C. Understanding and responding to adverse events. N Eng/ J Med 2003:348:1051-6. 